\title{
A variação na colocação pronominal da língua portuguesa falada no norte do Paraná
}

\author{
The variation in the pronominal \\ placement of the spoken \\ portuguese language in the North \\ of Paraná
}

\author{
Andréia Caroline Lopes ${ }^{1}$ \\ http://orcid.org/0000-0002-5385-825X \\ Jacqueline Ortelan Maia Botassini ${ }^{2}$ \\ https://orcid.org/0000-0001-9456-1973
}

\begin{abstract}
Resumo: O presente trabalho, baseado na metodologia da Sociolinguística Variacionista, examinou a variação da colocação pronominal na língua falada de norte-paranaenses. Para a análise, observaram-se, como possíveis condicionadores do fenômeno linguístico em estudo, os fatores extralinguísticos sexo, faixa etária e grau de escolaridade. O corpus da pesquisa constitui-se de oito entrevistas de informantes norte-paranaenses pertencentes ao banco de dados de entrevistas gravadas e transcritas por Botassini (2013) para a realização de sua tese. Após a análise, verificou-se que os fatores extralinguísticos grau de escolaridade e sexo foram, respectivamente, o mais determinante para o uso do clítico na fala e o que apresentou mais casos de colocação pronominal de acordo com as prescrições gramaticais.
\end{abstract}

Palavras-chave: Variação; Colocação pronominal; Clíticos; Língua falada.

\footnotetext{
1 Universidade Estadual de Maringá. E-mail: lopesdeia@hotmail.com ${ }^{2}$ Universidade Estadual de Maringá. E-mail: jaqueortelan@gmail.com
} 


\begin{abstract}
The present work, based on the methodology of Variationist Sociolinguistics, examined the variation of the pronominal placement in the spoken language of North-Paraná. For the analysis, we observed, as possible conditioners of the linguistic phenomenon under study, the extralinguistic factors gender, age group and educational level. The corpus of the research consisted of eight interviews of North-Paraná informants belonging to the database of interviews recorded and transcribed by Botassini (2013) to carry out her thesis. After the analysis, it was verified that the extralinguistic factors of educational level and gender were, respectively, the most determinant for the use of the clitic in the speech and the one that presented more cases of pronominal placement according to the grammatical prescriptions.
\end{abstract}

Keywords: Variation; Pronominal placement; Clitics; Spoken language.

\title{
Introdução
}

Desde a colonização, a língua portuguesa vem sendo usada no Brasil, trazida pelos primeiros portugueses que aqui se instalaram e que deram início a uma imposição cultural e linguística sobre aqueles que já povoavam este País. Desde então, a mistura de povos e de línguas que ocorreu aqui gerou influências na língua falada, que é viva e passível de constante mudança. Partindo desse pressuposto, muitas variações da língua portuguesa são encontradas na fala dos brasileiros e não podem ser consideradas erros, uma vez que são resultado de diversas influências dessas misturas de dialetos, de povos e continuam a se alterar com o passar do tempo, adaptando-se de acordo com os locais em que a língua é usada e com a necessidade de cada falante em se comunicar com o seu próximo.

Um tópico que sofreu grande modificação na fala, mas que continua sendo prescrito pela gramática normativa de uma maneira que há muito não ocorre no uso real da língua, é a questão da colocação pronominal padrão. O posicionamento do pronome oblíquo na frase na variedade padrão ainda é uma incógnita para a grande maioria dos falantes do português brasileiro, haja vista que a escola regular ainda ensina as regras da gramática normativa de maneira sistemática, com pouco foco nos contextos reais de uso, fazendo o falante realizar a colocação pronominal de maneira meramente intuitiva, muitas vezes, valendo-se inclusive dos pronomes retos (por exemplo, "Eu vi ele" em lugar de "Eu o vi").

A gramática tradicional estabelece que a colocação dos pronomes oblíquos átonos ocorre sempre junto ao verbo, em três posições possíveis: antes (próclise), no meio (mesóclise) ou depois (ênclise). Patrocínio (2011) resume, em uma gramática escolar, as regras de colocação pronominal: 
- Próclise obrigatória - quando, antes do verbo, há fator de próclise: palavras negativas, advérbios, pronomes (relativos, indefinidos, demonstrativos), conjunções subordinativas. [...]

- Mesóclise obrigatória - quando o verbo, no futuro do presente ou no futuro do pretérito, inicia a oração. [...]

- Ênclise obrigatória - quando o verbo inicia a oração. [...] (PATROCíNIO, 2011, p. 673)

Há, entretanto, uma diferença entre o que é sistematizado pela gramática normativa e o que realmente acontece na fala do português brasileiro. Diversos pesquisadores (GALVES; NAMIUTI; SOUSA, 2006; CARNEIRO; GALVES, 2010; VAREJÃO, 2009; LEITE, 2006; GÖRSKI; COELHO, 2009; COAN; FREITAG, 2010; BAGNO, 2012) buscam os motivos que levam o falante a variar quanto ao uso da colocação pronominal.

Diante do exposto, este estudo da língua em uso, pautado na metodologia da Sociolinguística Variacionista, objetiva examinar a realização da colocação pronominal na língua portuguesa falada por norte-paranaenses. Pretende, ainda, (i) verificar se as variáveis extralinguísticas sexo, faixa etária e grau de escolaridade condicionam essa colocação e (ii) comparar a colocação pronominal realizada pelos norte-paranaenses com o que prescreve a gramática tradicional.

Para tanto, utilizou-se um corpus constituído de dados coletados de entrevistas gravadas e transcritas por Botassini (2013) para a realização de sua tese, intitulada Crenças e atitudes linguísticas: um estudo dos róticos em coda silábica no Norte do Paraná.

\section{FUNDAMENTAÇÃO TEÓRICA}

Galves, Namiuti e Sousa (2006) partem das teorias da gramática gerativa e dos processos de gramaticalização para categorizar historicamente, desde o século 14, a língua portuguesa, dividindo-a em Português Arcaico, Português Médio e Português Europeu Moderno. Nessa linha do tempo estabelecida, os autores mostram como a colocação do clítico em relação ao verbo tem sofrido alterações com o passar dos tempos: a ênclise era preferida no Português Arcaico, a próclise predomina no Português médio e a ênclise passa a ser categórica no Português Europeu Moderno. Dessa maneira, revelam que as posições proclíticas e enclíticas concorreram em cada época, sendo de maior ou menor prestígio, dependendo da cultura vigente, assim como a colocação do elemento interpolado, que se trata da "construção na qual o clítico pronominal não se apresenta contíguo ao verbo - ou noutros termos, na qual um outro constituinte sintático se 'interpola' entre o pronome e o verbo" (GALVES; NAMIUTI; SOUSA, 
2006, p. 49). Os autores revelam que sempre a escolha da variante teve ligação com formas negativas expressas nas orações.

Carneiro e Galves (2010) também se valem das teorias da gramática gerativa e dos processos de gramaticalização para mostrar mudanças que surgiram com o passar do tempo entre Português Clássico, Português Europeu e Português Brasileiro. Assim, apontam que, em cada contexto, um tipo de colocação pronominal foi preferida: a próclise, mais recorrente no Português Brasileiro e a ênclise, no Português Europeu. Já o Português Clássico, diferentemente do esperado, por ser cronologicamente a gramática inicial, compete não só com o Português Europeu, mas também com o Português Brasileiro no que diz respeito à variação ênclise/próclise.

Cuesta e Luz (1983), ao tratarem dos pronomes em sua gramática da língua portuguesa, descrevem como se dá a colocação dos clíticos em Portugal. Segundo as autoras, esse é um dos pontos mais complicados da sintaxe portuguesa, sendo essa colocação dependente, principalmente, da natureza finita ou infinita do verbo e do tipo de oração de que fazem parte. Seguindo esses parâmetros, descrevem em que contextos os pronomes átonos devem ser usados prepostos ou pospostos ao verbo principal da oração:

Com as formas finitas do verbo:

a) Nas orações afirmativas o pronome segue normalmente o verbo, unindo-se a este por um hífen.

Exemplos:

Ele julgava-se grande conhecedor do assunto

Estudara-o a fundo.

Contaste-lhe a história?

$[\ldots]$

Mas quando no sujeito figura um numeral, ambos ou mesmo, o reflexivo átono antepõe-se:

Os três homens se sentaram à mesa

Ambos se sentiram bem

Ele mesmo se julgava mal (CUESTA; LUZ, 1983, p. 493, grifos das autoras).

Depois de apresentarem uma breve descrição de várias regras para a colocação pronominal de Portugal, as autoras afirmam que, pela diferença de entonação e pelo caráter ligeiramente tônico dos pronomes no Brasil, a colocação dos clíticos realizada no PB difere muito da realizada no português europeu (PE). Elas afirmam que os pronomes átonos no PB 


\begin{abstract}
Não só precedem muitas vezes o verbo em casos em que tal não aconteceria em Portugal, ou se pospõem a ele noutros em que neste país é obrigatória a posição proclítica, como chegam a aparecer em início de frase, numa posição em que devido à sua atonicidade se tornariam quase impronunciáveis para um falante luso (CUESTA; LUZ, 1983, p. 497).
\end{abstract}

Petter (2007) desenvolve uma pesquisa investigando a influência das línguas africanas nas mudanças ocorridas no português europeu, resultando assim no português falado em países como Angola, Moçambique e até no Brasil. Segundo a autora, a hipótese de que as línguas africanas tenham influenciado o português brasileiro é muito válida pelo fato de haver variações que seguem as mesmas estruturas realizadas naquelas línguas, como é o caso do uso da colocação pronominal. Citando Chavagne (2005), Petter afirma que

\begin{abstract}
Apesar da instabilidade do nível morfossintático no nível dos ideoletos, observada em Angola, Chavagne (2005) enumera vários pontos comuns entre o PA e o PB [português africano e o português brasileiro], principalmente na língua corrente ou popular, transcritos abaixo, com acréscimo de exemplos colhidos de outras partes do trabalho do autor [...]

- colocação pronominal 'perturbada'. Em Angola o pronome parece não obedecer a nenhuma regra: Me ajuda ainda a pisar a fuba. \...) Só pode-se quando os pais saiam [...] (PETTER, 2007, p. 15, grifo da autora).
\end{abstract}

Com isso, Petter (2007) mostra que a variação pronominal que ocorre no Português Brasileiro se assemelha mais às variações presentes no Português de Angola e no Português de Moçambique do que no Português Europeu, o que pode, de algum modo, explicar o distanciamento entre o padrão europeu e o que de fato os falantes brasileiros realizam.

Varejão (2009) leva em consideração as dimensões continentais do Brasil para justificar inicialmente a grande variação linguística existente no país e a mistura de culturas que influenciaram na sua formação. Em seguida, estabelece uma perspectiva histórica que busca mostrar a evolução do português para uma língua genuinamente brasileira. Depois, apresenta a variação consolidada devido ao seu uso para a escrita literária "que colocava os clíticos onde mandassem os seus ouvidos", provando, desse modo, que a diferença entre o Português Europeu e o Português Brasileiro em relação à colocação pronominal "seria a questão da eufonia e não das mudanças que já registravam especificidades dos dois sistemas" (VAREJÃO, 2009, p. 127). Por fim, como exemplos de mudanças consolidadas no Português Brasileiro, a autora cita as particularidades com relação ao uso de pronomes e sua colocação por meio de diversas outras pesquisas já realizadas anteriormente. 
Galves (1993), no artigo intitulado O enfraquecimento da concordância no português brasileiro, apresenta inicialmente uma análise diacrônica da mudança no número de ocorrências de sujeitos e objetos nulos. A autora apresenta uma diminuição nas ocorrências de sujeitos nulos, o que poderia justificar a menor utilização da concordância verbal, uma vez que o sujeito expresso permite a identificação número-pessoal do verbo. Em contrapartida, ela aponta um aumento nas ocorrências de objetos nulos, o que implica a diminuição de utilização de clíticos.

Outra mudança verificada pela autora foi a substituição dos pronomes oblíquos átonos por pronomes tônicos em função de objeto, quando este é expresso. Além da queda drástica na utilização dos clíticos, Galves (1993) ainda aponta uma mudança na posição que o pronome ocupa em relação ao verbo. Ao comparar diacronicamente dois corpora diferentes, um de cartas e um de peças de teatro, ela aponta um aumento de ocorrências proclíticas nas peças teatrais, em que a situação de fala é mais natural, e um aumento de ocorrências de ênclise nas cartas, em que as regras da gramática padrão parecem influenciar mais.

Görski e Coelho (2009), no artigo Variação linguística e ensino de gramática, levam em conta a necessidade de inserir as teorias da Sociolinguística Variacionista no ensino regular da língua portuguesa. As autoras também analisam o que postulam os documentos oficiais com relação ao ensino e iniciam o seu texto mostrando um contexto histórico da língua portuguesa a fim de comprovar a necessidade das mudanças:

\footnotetext{
a) Português de Portugal: (i) construções aspectuais como estava a brincar: (ii) uso frequente de pronomes clíticos como em Eu vi-o na rua (para se referir a uma terceira pessoa); (iii) uso predominante de ênclise como em Diga-me uma coisa; (iv) emprego do verbo haver no sentido de existir como em Há fogo naquela casa.

b) Português do Brasil: (i) construções aspectuais como estava brincando; (ii) uso predominante de objeto nulo (ou de pronome tônico) em lugar do clítico, como Eu vi Ø na rua e Eu vi ele na rua (para se referir a uma terceira pessoa); (iii) uso predominante de próclise como em Me diga uma coisa; (iv) emprego do verbo ter (ao invés de haver) no sentido de existir como em Tem fogo naquela casa. (GÖRSKI; COELHO, 2009, p. 76).
}

As autoras levam em consideração também a questão da norma e tentam diferenciar, assim como Bagno (2002), norma padrão e norma culta. Por fim, apresentam algumas mudanças nos quadros pronominais do português brasileiro. 


\begin{abstract}
Embora a noção de norma padrão não se confunda com a de norma culta (a primeira corresponde a regras impostas e a segunda, a padrões efetivos de uso observável num certo grupo social), há uma aproximação entre elas [...]

Entretanto, há muitos casos de desacordo entre a prescrição normativa e o uso culto. Eis alguns: (i) A regra geral de colocação do pronome átono (clítico) é a ênclise, como em Ele veio interromper-me; porém, salvo alguns poucos casos, a tendência de uso do brasileiro é a próclise: Ele veio me interromper. (GÖRSKI; COELHO, 2009, p. 80)
\end{abstract}

Coan e Freitag (2010) também estudaram a necessidade da adequação do ensino de língua portuguesa na escola com base em conceitos da Sociolinguística Variacionista. Partindo desse pressuposto, as autoras primeiramente discorreram sobre as teorias que serviriam como base para a possível mudança no ensino:

\begin{abstract}
Os pressupostos teórico-metodológicos da Sociolinguística Variacionista (LABOV, [1972] 2008; 1978; 1994; 2001; 2003; 2010) desencadearam propostas de ensino assentadas: i) na correlação entre língua e sociedade; ii) na análise linguística de regras variáveis condicionadas por fatores linguísticos e extralinguísticos; e iii) na minimização de preconceitos vigentes na sociedade. (COAN; FREITAG, 2010, p. 174).
\end{abstract}

Seguindo as teorias que defendem os estudos linguísticos, as autoras passaram então a compará-los às práticas de ensino e de uso da língua portuguesa do Brasil a fim de verificar a possibilidade de inserção desses novos pressupostos teóricos aos documentos oficiais que norteiam o ensino da língua portuguesa nas escolas regulares.

Especificamente em relação à variação na colocação pronominal, as autoras assim se expressam:

\begin{abstract}
Já em Pronominais, Oswald ilustra a regra variável da colocação pronominal no português. Os pronomes do caso oblíquo átonos, no português, podem ocorrer em três posições: antes do verbo (próclise), no meio do verbo (mesóclise) e depois do verbo (ênclise). Em princípio, cada tipo de colocação se dá em função das motivações do ambiente linguístico em que ocorre. Entretanto, existe uma forte motivação sociocultural que impera na escolha de uma ou outra colocação: o reconhecimento de que o português falado no Brasil é diferente do português falado em Portugal. (COAN; FREITAG, 2010, p. 189).
\end{abstract}

Bagno (2012) busca diferenciar os conceitos de normal e normativo, trazendo, para tanto, a definição de norma culta e norma padrão. A partir disso, o autor mostra que diversas 
regras prescritas pela gramática tradicional e tidas como norma padrão não são aplicadas na fala, nem mesmo dos falantes mais escolarizados. Na sequência, Bagno (2012) ilustra o uso da colocação pronominal na fala de indivíduos considerados cultos e que supostamente deveriam utilizar as regras impostas pela gramática tradicional. Constata-se, contudo, que o previsto não ocorre.

Na seção 2, a seguir, apresentam-se dados sobre a metodologia utilizada na pesquisa que originou o presente artigo.

\section{CORPUS E METODOLOGIA}

Este estudo baseia-se na metodologia da Sociolinguística Variacionista, que teve como precursor William Labov. Segundo Tarallo (1986, p. 07), esse modelo “apresenta-se como uma reação à ausência do componente social no modelo gerativo", que considera, para fins de estudos linguísticos, um falante ideal e que pertence a uma comunidade linguística homogênea. A Sociolinguística, porém, entende a língua falada como um sistema heterogêneo, que se relaciona com as variáveis sociais (sexo, faixa etária, grau de escolaridade etc.) e que está em constante modificação. Sendo assim, é a heterogeneidade, a diversidade linguística, o objeto de estudo da Sociolinguística.

O corpus desta pesquisa constitui-se de dados coletados do banco de entrevistas consttuído por Botassini (2013) Esse banco de dados é composto por 48 entrevistas, sendo os informantes divididos igualmente por região de origem (16 norte-paranaenses, 16 gaúchos e 16 cariocas).

A escolha desse corpus se deu pelo interesse em utilizar um banco de dados de coleta mais recente (as entrevistas foram realizadas por Botassini entre 2011 e 2012) e que pudesse retratar, assim, a língua falada atualmente. Leite (2006) assevera que o tópico colocação pronominal é uma questão "controversa" e que acabou adquirindo muito "relevo e visibilidade" por carregar consigo uma questão política e identitária de língua praticada neste País. Ela afirma que, por se tratar de um fenômeno linguístico que é alvo de variação, deve ser analisado partindo-se de usos mais recentes da linguagem.

Das 48 entrevistas que compõem o corpus, analisaram-se 8, mais especificamente, 8 entrevistas de informantes norte-paranaenses, divididos igualmente por sexo (quatro homens e quatro mulheres), por faixa etária (quatro informantes da 1. a FE, com idades entre 20 e 35 anos, e quatro da $2 .^{a} \mathrm{FE}$, entre 50 e 65 anos) e por grau de escolaridade (quatro informantes com formação superior e quatro com ensino médio). 
As oito entrevistas transcritas selecionadas foram lidas a fim de (i) detectar a ocorrência dos clíticos nas falas dos informantes, (ii) classificar a colocação dessas ocorrências em próclise, mesóclise ou ênclise e (iii) verificar como se deu a colocação pronominal. As ocorrências encontradas nas falas do documentador não foram contabilizadas. Assim, obtiveram-se 156 ocorrências de pronomes clíticos, sendo 154 em posição de próclise e apenas 2 em posição de ênclise. Nenhuma ocorrência foi encontrada em posição de mesóclise.

Em seguida, as amostras foram divididas entre sexo (feminino e masculino), faixa etária (1. ${ }^{a} \mathrm{FE}$ e 2. ${ }^{\mathrm{a}} \mathrm{FE}$ ) e grau de escolaridade (formação superior e ensino médio) e os dados coletados foram contabilizados e expressos em gráficos e tabelas para posterior análise quantitativa e qualitativa.

\section{ANÁLISE DOS DADOS}

Na análise de dados, foram encontrados 156 casos de clíticos. Desses 156 casos, 154 (98,7\%) estavam em posição proclítica e apenas 2 (1,3\%) em posição enclítica.

Tabela 1 - Ocorrência dos clíticos.

\begin{tabular}{l|c|c}
\hline \multicolumn{1}{c|}{ Posição } & Ocorrências & $\%$ \\
\hline Próclise & 154 & 98,7 \\
\hline Ênclise & 2 & 1,3 \\
\hline Total & 156 & 100 \\
\hline
\end{tabular}

Esse resultado ratifica o de outros trabalhos que destacam a preferência pela próclise, no português do Brasil, ainda que as gramáticas de base tradicional insistam em apresentar a ênclise como a colocação "lógica, normal".

Tratando-se dos dois casos de ênclise encontrados, ambos se apresentam na fala de informantes da segunda FE e com ensino superior, um masculino e um feminino. Contudo apenas uma das ênclises foi usada de acordo com a prescrição normativa:

"Eu até gosto de ouvi-los [...]".

Enquanto a outra ocorrência de ênclise não segue a gramática prescritiva, pois havia elemento que atraía para próclise. Essa ocorrência foi realizada, muito provavelmente, como resultado de uma hipercorreção: 
"...eu julgo que fala-se muito errado."

Quanto aos 154 casos de próclise, 88 ocorrências (57,1\%) estão em conformidade com as prescrições gramaticais, visto que havia elementos "atrativos" de próclise (palavras negativas, advérbios, orações subordinadas etc.), como:

"...eu nunca me senti tão triste."

Enquanto 66 casos (42,9\%) não correspondem às normas estabelecidas pela gramática normativa. São situações em que as prescrições gramaticais exigem o emprego da ênclise (início de orações, verbos no gerúndio, imperativo etc.) e um caso em que se determina o uso da mesóclise (verbo no futuro):

“...minha mãe me ligando no celular."

Os pronomes clíticos encontrados no corpus foram os seguintes: me, se, te, nos e os (este último na forma los). Desses, o mais usado pelos entrevistados foi o pronome me, que sozinho constitui quase dois terços dos dados coletados. Vale ressaltar ainda que todas as ocorrências do pronome nos foram realizadas na fala de um único informante e a forma pronominal -los apareceu apenas uma vez, em um caso de ênclise. Analisando-se ainda a função desses pronomes nas orações, tem-se uma grande maioria deles usados como acusativos, o que possibilita levantar a hipótese de que o fator linguístico objeto direto é condicionador para o uso dos pronomes encontrados neste levantamento. Para provar esse pressuposto, contudo, serão necessários mais estudos.

\subsection{FATORES EXTRALINGUÍSTICOS}

Em seguida, analisam-se os fatores extralinguísticos sexo, faixa etária e grau de escolaridade com o objetivo de verificar se são condicionadores de uso dos pronomes clíticos, bem como de sua colocação. 


\subsubsection{SEXO}

Das 156 ocorrências encontradas nas oito entrevistas analisadas, 87 apareceram nas falas de informantes femininas (56\%) e 69 nas falas de informantes masculinos (44\%), conforme ilustrado no gráfico seguinte:

Gráfico 1 - Representação do percentual de uso de pronomes clíticos entre homens e mulheres.

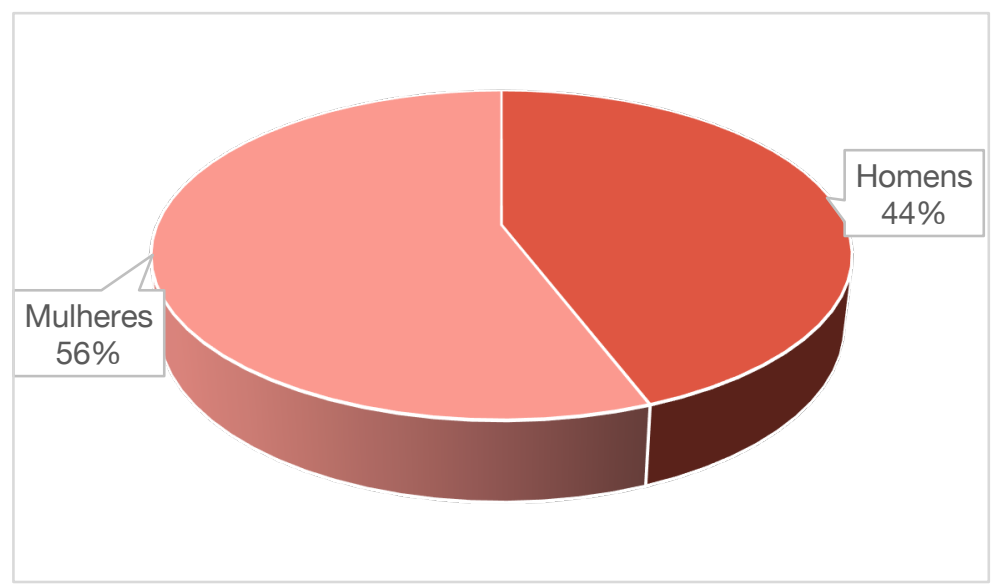

Esse resultado aponta que o fator extralinguístico sexo se mostra relevante com relação ao uso mais frequente do clítico pelas mulheres. Pesquisas anteriores apontam a mulher como falante mais conservadora e isso se confirma com esse dado.

Além de produzirem maior número de usos dos pronomes clíticos, no que diz respeito à colocação desses pronomes em relação ao verbo, as mulheres ainda têm maior percentual de de dados em acordo com o que determina a gramática tradicional.

Assim, esses dados apontam para a teoria defendida por Labov (2008) de que a mulher tende a se preocupar mais com o status linguístico do que o homem e só utiliza uma determinada variante quando essa não é mais estigmatizada. Além disso, Labov (2008) assevera que as mulheres são as propulsoras das mudanças linguísticas.

Paiva (2003) também reitera que a mulher parece ser mais sensível às normas de linguagem e que o uso das formas de prestígio da língua tem maior predomínio na sua fala. Ademais, a autora ressalta que os estudos relacionados a essa variável demandam certa 
prudência devido aos papéis sociais ocupados pela mulher ou pelo homem em determinadas comunidades de fala, o que pode levar a comportamentos linguísticos distintos, considerando a interação com outras variáveis possíveis de serem encontradas em contextos diversos. Por exemplo,

\begin{abstract}
Se nos situamos no contexto cultural das sociedades ocidentais, a predominância de variantes padrão entre mulheres mais velhas reflete uma forma de organização mais rígida em que ao homem cabe desempenhar seu papel de homem e à mulher seu papel de mulher. Dentre as boas atitudes que se espera de uma mulher está o uso de uma linguagem mais correta, condizente com a sua condição feminina. Transformações na organização social podem estar subjacentes à neutralização do efeito da variável gênero/sexo nas faixas mais jovens da população. A aproximação do comportamento linguístico de falantes mais jovens pode ser um reflexo de que, nessa faixa etária, reconfigura-se a atuação do homem e da mulher na sociedade, com diluição das fronteiras entre papéis femininos e masculinos (PAIVA, 2003, p. 41).
\end{abstract}

\title{
3.1.2 FAIXA ETÁRIA
}

Com relação ao fator extralinguístico faixa etária $(\mathrm{FE})$, os resultados apontam maior ocorrência de clíticos nos informantes da primeira FE, com 99 realizações (63\%), contra 57 ocorrências (37\%) encontradas na segunda FE, conforme ilustra o gráfico seguinte:

Gráfico 2 - Representação do percentual de uso de pronomes clíticos entre $1 .{ }^{\mathrm{a}} \mathrm{FE}$ e $2 .^{\mathrm{a}} \mathrm{FE}$.

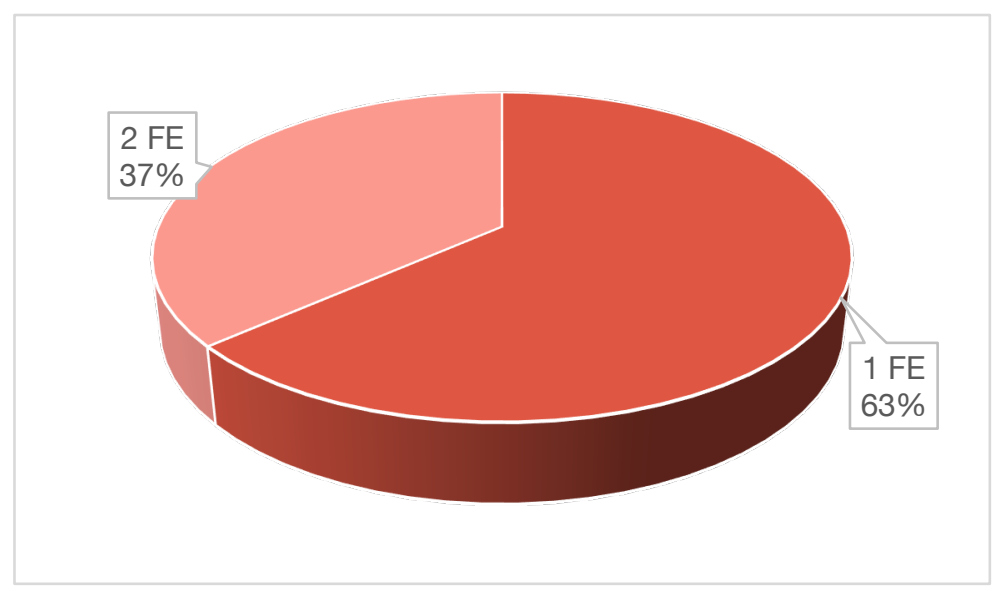


Ao analisar esse fator, o resultado encontrado foi diferente do esperado. Conforme aponta Galves (1993), as mudanças linguísticas tendem a ocorrer diacronicamente, ou seja, com o passar do tempo, o falante passa a alterar a sua própria língua e, dessa forma, surgem as inovações que se consolidam e passam a ser socialmente aceitas. Normalmente essas mudanças figuram principalmente na fala de indivíduos mais jovens, o que não foi constatado aqui. É importante ressaltar, entretanto, que das 99 ocorrências de clíticos registradas na primeira FE, 50 apareceram na fala de uma única informante que possui ensino superior. Ou seja, uma informante sozinha produziu mais de $50 \%$ dos clíticos contabilizados, o que traz um desvio nos resultados e, portanto, não permite fazer considerações conclusivas sobre essa variável.

Outro ponto importante a se levar em conta é que, de um universo de 48 entrevistas que compõem o banco de dados utilizado neste trabalho, apenas 8 foram analisadas, sendo necessárias mais análises em maior número de entrevistas para obter resultados mais consistentes em relação a essa variável.

Com relação à colocação desses pronomes, ainda que a primeira FE tenha produzido maior número de clíticos, ela apresenta também maior percentual de colocações em desacordo com a norma (51\%), ao passo que a segunda FE apresenta 30\% das ocorrências diferentes do que prescreve a gramática tradicional.

\subsubsection{GRAU DE ESCOLARIDADE}

Por fim, ao se tratar do grau de escolaridade dos informantes, das 156 ocorrências encontradas, 29 (19\%) apresentam-se na fala de informantes com ensino médio, enquanto 127 (81\%) estão na fala de informantes com ensino superior, conforme representado pelo gráfico 3 , a seguir: 
Gráfico 3 - Representação do percentual de uso de pronomes clíticos entre informantes com ensino médio e com ensino superior.

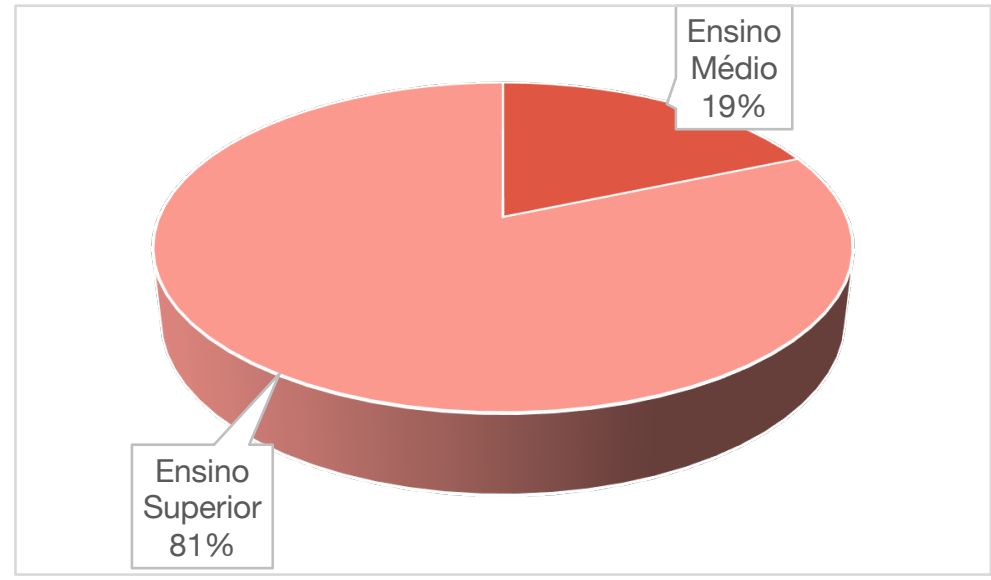

Conforme se supunha, esse resultado revela que a variável escolaridade se apresenta como altamente condicionadora do uso do clítico. Parece indicar, ainda, que o tempo de exposição aos bancos escolares e, consequentemente, o contato com leitura e com textos escritos favorecem o uso de formas pronominais clíticas.

Ressalta-se, porém, que o grande número de ocorrências não necessariamente significa o cumprimento das normas gramaticais do padrão linguístico determinadas para a colocação pronominal. Das 127 ocorrências encontradas nas falas dos informantes com ensino superior, $48 \%$ delas estava em desacordo com a norma padrão. E dos 29 casos de clíticos nas falas dos informantes de ensino médio, 20\% não seguiam a prescrição da gramática tradicional.

Apesar do número de ocorrências ser tão discrepante entre os dois grupos em estudo, a quantidade maior não necessariamente representa mais fidelidade à gramática normativa, uma vez que, analisando-se proporcionalmente, os falantes mais escolarizados e expostos por mais tempo aos bancos escolares não seguiram necessariamente as regras gramaticais. Essas regras, como se pôde perceber, estão muito distantes dos usos do português brasileiro, mesmo do falante mais escolarizado.

\section{Considerações finais}

Os resultados obtidos neste recorte inicial (lembrando que foram analisadas apenas 8 das 48 entrevistas que compõem o banco de dados) revelam a utilização de 98,7\% de clíticos 
em posição proclítica. O uso praticamente categórico desse tipo de colocação aponta que, ao menos na fala, a próclise, na língua portuguesa brasileira, é um fenômeno linguístico praticamente categórico.

Em relação às variáveis analisadas, observou-se que há um alto condicionamento da ocorrência de clíticos na variável grau de escolaridade, ou seja, quanto mais escolarizado o informante, mais uso faz de clíticos em seu discurso, porém quase a metade desses usos não ocorre conforme determina a tradição. Constatou-se ainda a produção mais próxima do que determina a tradição nas falas do sexo feminino, o que reforça a teoria de que as mulheres produzem um discurso mais polido, mais preocupado com o status linguístico, mais conservador. Quanto ao fator faixa etária, o resultado encontrado diverge do que era esperado, levando em conta os processos diacrônicos de mudança da língua; entretanto, devido ao fato de uma única informante ter produzido, em seu discurso, um número de clíticos excessivo (em comparação com os demais informantes), isso pode ter enviesado os resultados, não se podendo fazer maiores considerações.

Por fim, é importante reforçar que este é um estudo inicial e que outras investigações sobre esse tópico serão realizadas a fim de levantar um número maior de dados e apresentar resultados mais concretos no que diz respeito a esse fenômeno linguístico.

\section{REFERÊNCIAS}

BAGNO, Marcos. Norma linguística, hibridismo \& tradução. Traduzires 1, Maio, 2012. Disponível em $<$ http://www.repositorio.unb.br/bitstream/10482/10546/1/ARTIGO_Norma Linguistica Hibridismo.pdf >. Acesso em: 10 de out. de 2017.

BOTASSINI, Jacqueline Ortelan Maia. Crenças e atitudes linguísticas: um estudo dos róticos em coda silábica do norte do Paraná. 2013. 219f. Tese (Doutorado em Estudos da Linguagem). Universidade Estadual de Londrina, Londrina.

CARNEIRO, Zenaide; GALVES, Charlotte. Variação e Gramática: colocação de clíticos na história do português brasileiro. Revista de Estudos da Linguagem, Belo Horizonte, v. 18, n. 2, p. 7-38, jul./dez. 2010.

COAN, Márluce; FREITAG, Raquel Meister Ko. Sociolinguística variacionista: pressupostos teóricometodológicos e propostas de ensino. DOMÍNIOS DE LINGU@GEM: Revista Eletrônica de Linguística (http://www.seer.ufu.br/index.php/dominiosdelinguagem). Volume 4, n. 2 - 2. ${ }^{\circ}$ Semestre 2010 - ISSN 1980 5799.

CUESTA, Pilar Vázquez; LUZ, Maria Albertina Mendes da. Gramática da língua portuguesa. Lisboa: Edições $70,1983$.

GALVES, Charlotte C. O enfraquecimento da concordância no português brasileiro. In: ROBERTS, Ian; KATO, Mary (orgs.). Português brasileiro: uma viagem diacrônica. Campinas: Editora da Unicamp, 1993. p. 387-408.

GALVES, Charlotte; NAMIUTI, Cristiane; SOUSA, Maria Clara Paixão de. Novas perspectivas para antigas questões: revisitando a periodização da língua portuguesa. In: ENDRUSCHAT, A.; KEMMLER, R.; SCHAFER- 
PRIET, B. (orgs.). Grammatische Strukturen des Europaischen Portugiesich. Tubingen: Calepinus, 2006. p. 45-75.

GÖRSKI, Edair Maria; COELHO, Izete Lehmkuhl. Variação linguística e ensino de gramática. Work. pap. linguíst., 10 (1): 73-91, Florianópolis, jan. jun., 2009. Disponível em $<$ https://periodicos.ufsc.br/index.php/workingpapers/article/view/1984-8420.2009v10n1p73/120 22>. Acesso em 03 de out. de 2017.

LABOV, William. Padrões sociolinguísticos. São Paulo: Parábola Editorial, 2008.

LEITE, Marli Quadros. A nova gramática do português contemporâneo: tradição e modernidade. Filologia 7.pmd, $24 / 7 / 2007$.

PAIVA, Maria da Conceição de. A variável gênero/sexo. In: MOLLICA, Maria Cecilia; BRAGA, Maria Luiza (orgs.). Introdução à sociolinguística: o tratamento da variação. São Paulo: Contexto, 2003. p. 33-42.

PATROCíNIO, Mauro Ferreira do. Aprender a praticar gramática. Volume único. São Paulo: FTD, 2011.

PETTER, Margarida Maria Taddoni. Uma hipótese explicativa do contato entre o português e as línguas africanas. Revista Brasileira de Estudos do Contato Linguístico: PAPIA, v. 17, 2007. p. 9-19.

TARALLO, Fernando. A pesquisa sociolinguística. 2. ed. São Paulo: Ática,1986.

VAREJÃO, Filomena de Oliveira Azevedo. O português do Brasil: revisitando a história. Cadernos de Letras da UFF - Dossiê: Difusão da língua portuguesa, n. 39, p. 119-137, 2009. Disponível em $<$ http://www.cadernosdeletras.uff.br/joomla/images/stories/edicoes/39/artigo6. pdf $>$. Acesso em: 03 de out. de 2017. 